\title{
Read the Paper! Re: Cheng/Ho Point/Counterpoint on Electrodiagnostic Testing Before Surgery for Spinal Stenosis
}

To the Editor,

The point-counterpoint between spine surgeon Ivan Chang and physiatrist Suehun Ho is a wonderful platform for rational discussion [1]. Dr Chang's intentions are good, and I think we all are grateful for his effort to reach across professional boundaries. However, his comments include important misrepresentations and misinterpretations of our work that live on in the spine literature despite our previous commentary [2]. I feel obligated to correct him. Specifically:

- The false belief that the cross-sectional area of the dural sac was not measured in our study and that the dural sac measurement is "a more appropriate measurement of central canal stenosis." In fact, we measured thecal sac areas and diameters, as well as spinal canal areas and diameters at 4 lumbar levels [3]. The Journal of Bone and Joint Surgery perhaps unwisely decided to put this important table in an online appendix. The thecal sac measures had no correlation whatsoever with the clinical syndrome. The idea that thecal sac measures are somehow more valid than canal diameters is a half-century old dogma justified by the authors by citing a 20-year-old article in which Hamanishi et al report an uncontrolled, unmasked retrospective study that compares 44-year-old (average age) patients with back pain and 45-year-old patients with sciatica to 62-year-old patients with neurogenic claudication [4]. The article's conclusion was also about "developmental" stenosis (short pedicles), not degenerative stenosis. Today there remains no specific magnetic resonance imaging (MRI) measure or radiologist impression that

\footnotetext{
A.J.H. Disclosures outside this publication: board membership, AAPMR, AANEM, ISPRM, IRF (unpaid volunteer positions); employment, consulting (money to author); expert testimony, occasional case review, Best Doctors, Inc (money to author); payment for lectures including service on speakers bureaus, various academic institutions (money to author); travel/accommodations/meeting expenses unrelated to activities listed, various academic institutions (money to author)
}

has proven useful in positively diagnosing symptomatic stenosis.

- The wrong statement that our study found that electrodiagnosis (EDX) was abnormal in 50\% of asymptomatic persons and $50 \%$ of persons with clinical stenosis - thus useless. No data for any scenario in our article approximated the 50\%-50\% numbers $\mathrm{Dr}$ Chang cites. Table 2 compares EDX findings in asymptomatic subjects to persons with clinically based stenosis, providing a spectrum of possible scenarios such as fibrillations in limb or back muscles ( 4 times more likely to be abnormal in persons with stenosis), paraspinal fibrillations (3 times as likely), and limb fibrillations (10 times as likely). The weakest example, "20\% polyphasic motor units in any muscle," found in about $40 \%$, not $50 \%$ of both populations, is one that few clinicians would espouse. The EDX findings in persons with clinical stenosis are radically different from the EDX findings in asymptomatic volunteers.

- The unsupported idea that limb electromyography is not proven useful. In our Table 2, people with stenosis were 10 -fold more likely to have limb fibrillations than were the asymptomatic volunteers. Highquality research basic to the specialty and too extensive to cite here finds that the limb examination is critical in positively diagnosing a myriad of neuromuscular disorders that can mimic stenosis.

- The wrong contention that our comparison only involved asymptomatic control subjects. Table 1 comparing 51 persons with clinical stenosis to 44 persons with mechanical low back pain shows equally excellent evidence for EDX and equally damning evidence against MRI. Again, the online appendix includes thecal sac and other measures that were found nondiscriminatory.

- The unsubstantiated belief that patients with atypical findings are "few and far between." Despite extensive prescreening and expert examinations, 8 of $150(5 \%)$ of subjects entering into our study were rejected after EDX alone found a neuromuscular disease. In another idealized situation, we screened 
out other diseases and required spine surgeons to perform an exhaustive history and physical examination [5]. Nine of $43(21 \%)$ of people offered spine surgery by university faculty spine surgeons were thought by the masked surgeons to be asymptomatic volunteers.

Stenosis surgery is a good thing for the right patient. I might even give some latitude regarding electromyographic testing in the theoretical "perfect" case presented in this point/counterpoint. However, given the embarrassing surgical epidemiology cited by $\mathrm{Dr} \mathrm{Ho}$, the idea that community surgeons, biased by decades of false confidence in MRI images, performing a history and physical examination that is likely less extensive than the examination we required for this study, in patients who are not extensively prescreened by someone else against the differential diagnosis, will make the correct diagnosis and restrain themselves from plying their profitable trade represents pure hubris. As a general policy, an expert opinion by someone who is not a surgeon is a must, and before anyone cuts, electrodiagnostic testing should be performed in all but the most perfectly healthy patients with classic symptoms and a clear surgical target.

Andrew J. Haig, MD

Physical Medicine and Rehabilitation

University of Michigan

Ann Arbor, MI

\section{References}

1. Chung I, Ho S. Point/counterpoint: Electrodiagnostic testing before surgery for spinal stenosis. PM R 2014;6:945-950.

2. Haig AJ. Diagnostic tests the NASS stenosis guidelines. Spine J 2014; 14:200-201.

3. Haig AJ, Geisser ME, Tong HC, et al. Electromyographic and magnetic resonance imaging to predict lumbar stenosis, low-back pain, and no back symptoms. J Bone Joint Surg Am 2007;89:358-366.

4. Hamanashi C, Matukura N, Fujita M, Tomihara M, Tanaka S. Cross sectional area of the stenotic lumbar dural tube measured from the transverse views of magnetic resonance imaging. J Spinal Dis 1994; 7:388-393.

5. Haig AJ, Park P, Henke PK, et al. Reliability of the clinical examination in the diagnosis of neurogenic versus vascular claudication. Spine J 2013;13:1826-1834. 